\title{
Simulation of a coastal jet retention process using a barotropic model
}

\author{
Pierrick PENVEN $^{a, b *}$, Claude ROY ${ }^{a}$, Alain COLIN de VERDIÈRE ${ }^{b}, J_{0 h n}$ LARGIER $^{\mathrm{c}}$ \\ ${ }^{a}$ Oceanography Department, University of Cape-Town, Rondebosch 7701, South Africa \\ ${ }^{\mathrm{b}}$ Laboratoire de Physique des Océans, Université de Bretagne Occidentale, 6, Av. Victor-Le-Gorgeu, BP809, \\ 29285 Brest cedex, France \\ ${ }^{\mathrm{c}}$ Scripps Institution of Oceanography, University of California (San Diego), La Jolla, CA 92093-0209, USA
}

\begin{abstract}
In the southern Benguela, sardine and anchovy spawn on the Western Agulhas Bank. Eggs and larvae are transported to the West coast nursery ground by a coastal current. Once the larvae reach the West coast, retention within the favorable coastal domain is key to larvae survival and recruitment. The Cape Columbine-St Helena Bay area is the main nursery ground along the West Coast. In this area, the interaction between upwelling and topography results in the formation of an upwelling plume. The plume, and the associated circulation patterns, is thought to be the mechanism providing retention within the coastal domain. The dynamics of the plume are studied using a set of numerical experiments. It is shown that an equatorward wind forcing produces a cyclonic eddy in the lee of Cape Columbine. A balance between advection and bottom friction regulates the evolution of this eddy. The eddy contributes to create a dynamic boundary between the coastal and the offshore domains. Retention induced by the eddy is quantified using a tracer. The magnitude of retention is positively related to the wind for weak to moderate wind intensities. For strong wind intensity, retention reaches a maximum or slightly decreases. This is in agreement with previous results relating recruitment success with wind speed. (C) 2000 Ifremer/CNRS/IRD/Éditions scientifiques et médicales Elsevier SAS
\end{abstract}

Résumé - La circulation dans un upwelling résulte d'interactions entre les processus physiques méso-échelles : tourbillons, structures frontales et courants se forment sur le plateau et controlent la dynamique spatiale des ressources vivantes. Dans des milieux dispersifs comme les upwellings, l'adaptation étroite entre les stratégies développées par les populations marines et la circulation facilite l'identification des contraintes environnementales agissant sur le vivant. Deux éléments ont un rôle particulièrement important: la rétention (dérive ou maintien des composantes biologiques vers ou dans les zones favorables) et la concentration (fronts, convergence, stratification). À l'aide d'un modèle simplifié de la circulation dans le Sud-Benguela, on se propose de quantifier l'importance de ces processus de rétention sur le recrutement des populations locales de sardines et d'anchois. Dans le Sud-Benguela, sardines et anchois migrent pour pondre à l'extrémité ouest du banc des Aiguilles. Les oeufs et les larves sont ensuite transportés par un jet côtier vers les nourriceries de la côte Ouest de l'Afrique du Sud. À l'intérieur de ces zones côtières, la rétention est essentielle pour la survie des larves et le recrutement des deux espèces. Dans la zone cap Colombine-baie de Sainte Hélène, l'interaction entre l'upwelling et la topographie entraîne la formation d'un panache d'upwelling en aval du cap Colombine et d'une zone de rétention qui assure le maintien des larves et juveniles dans la bande côtière. La dynamique du panache est étudiée à partir d'une série d'expériences numériques. On montre qu'un vent soufflant vers l'équateur produit un tourbillon cyclonique en aval du cap Colombine. Un équilibre entre l'advection et la friction de fond contrôle son évolution. Cette zone de recirculation contribue à la création d'une frontière dynamique entre les domaines côtiers et hauturiers. La rétention ainsi produite est quantifiée par un traceur mesurant l'âge de l'eau. Elle est liée à la force du vent pour des valeurs faibles à modérées. Pour des vents plus forts, elle atteint un maximum

\footnotetext{
* Correspondence and reprints:

E-mail address: penven@diaoul.sea.uct.ac.za (P. PENVEN).
}

(C) 2000 Ifremer/CNRS/IRD/Éditions scientifiques et médicales Elsevier SAS.

PII: S0399-1784(00)01106-3/FLA 
ou décroît doucement, ce résultat est en accord avec des travaux antérieurs. C 2000 Ifremer/CNRS/IRD/Éditions scientifiques et médicales Elsevier SAS

Benguela / cape effects / modeling / retention / recruitment

\section{Benguela / effets de cap / modélisation / rétention / recrutement}

\section{INTRODUCTION}

Retention processes that allow pelagic fish eggs and larvae to be retained within nursery grounds are considered as one of the major environmental processes affecting fish reproductive strategies (Bakun, 1996). To avoid offshore loss of their reproductive material, fish usually avoid reproducing in upwelling centers or during periods of active upwelling (Parrish et al., 1983). In some areas, the spatial structure of the upwelling allows a positive coupling between upwelling and retention (Bakun, 1998). Several studies have shown that upwelling plumes can contribute to provide retention, and that fish spawning is often

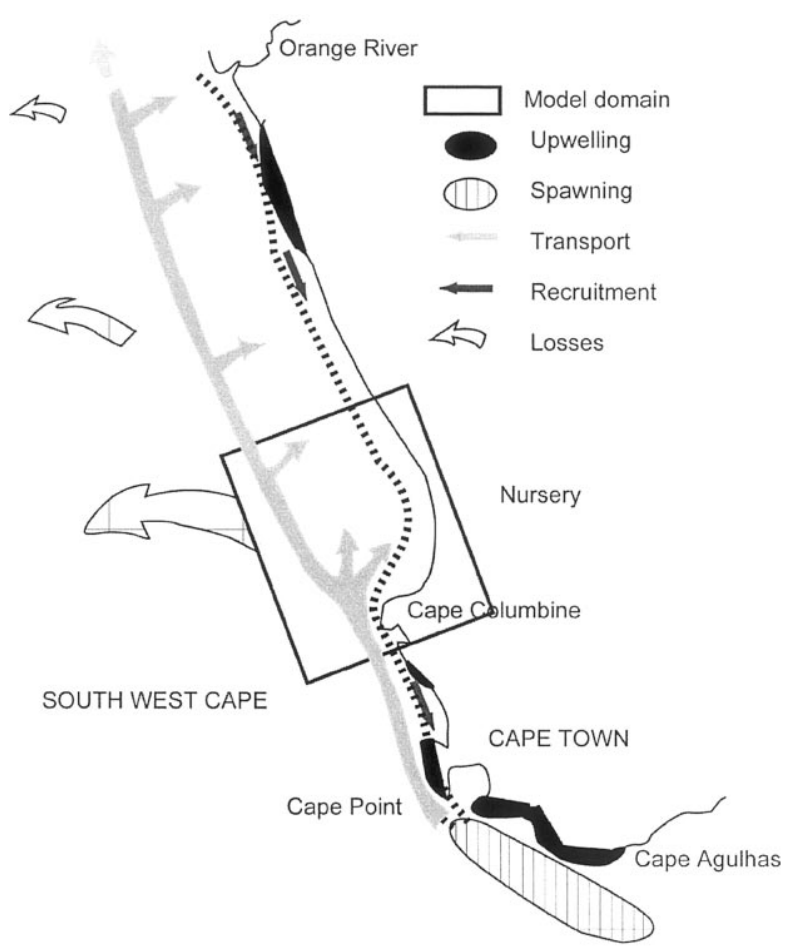

Figure 1. The Southern Benguela upwelling system with the main processes affecting recruitment of sardines and anchovies. associated with such structures (Graham and Largier, 1997; Roy, 1998). However, physical dynamics of these plumes remain poorly understood. The purpose of this study is to explore and understand the mechanisms responsible for the formation of this environmental feature using simple numerical modeling tools and the Southern Benguela upwelling system as a case study.

In the southern Benguela upwelling system, the most important nursery ground for sardines and anchovies is located in the Cape Columbine upwelling area (figure 1). This area lies between the coast and the shelf break, and is dynamically bounded by the Cape Peninsula upwelling area in the south $\left(33.5^{\circ} \mathrm{S}\right)$ and the Hangklip Bay upwelling cell in the north $\left(31.5^{\circ} \mathrm{S}\right)$ (Shannon, 1985). The shallow shelf region immediately north of Cape Columbine is known as St Helena Bay. During upwelling events, maps of sea surface temperature show an upwelling plume extending from Cape Columbine and bending eastward into St Helena Bay (Taunton-Clark, 1985). A numerical model of the circulation in this area is implemented in order to investigate the physical dynamics of the plume and their contributions to provide retention within St Helena Bay.

The area of interest extends $300 \mathrm{~km}$ alongshore and $200 \mathrm{~km}$ cross-shore (figure 1). The shelf break is quasi-rectilinear, running northwestward roughly parallel to the coast (figure 2a). South of Cape Columbine, the width of shelf is narrow $(50 \mathrm{~km})$ and becomes broader further north (figure $2 a$ ). Upwelling favorable southeasterly winds prevail in summer. They are modulated on a typical period from 5 to 6 days by the eastward moving cyclones and the passing trough of coastal lows (Nelson and Hutchings, 1983). The Cape Columbine upwelling plume develops during upwelling events. Kamstra (1985) and Jury (1985) have related the generation of the plume to the cyclonic wind stress curl in the vicinity of Cape Columbine. This curl is generated by topographic 


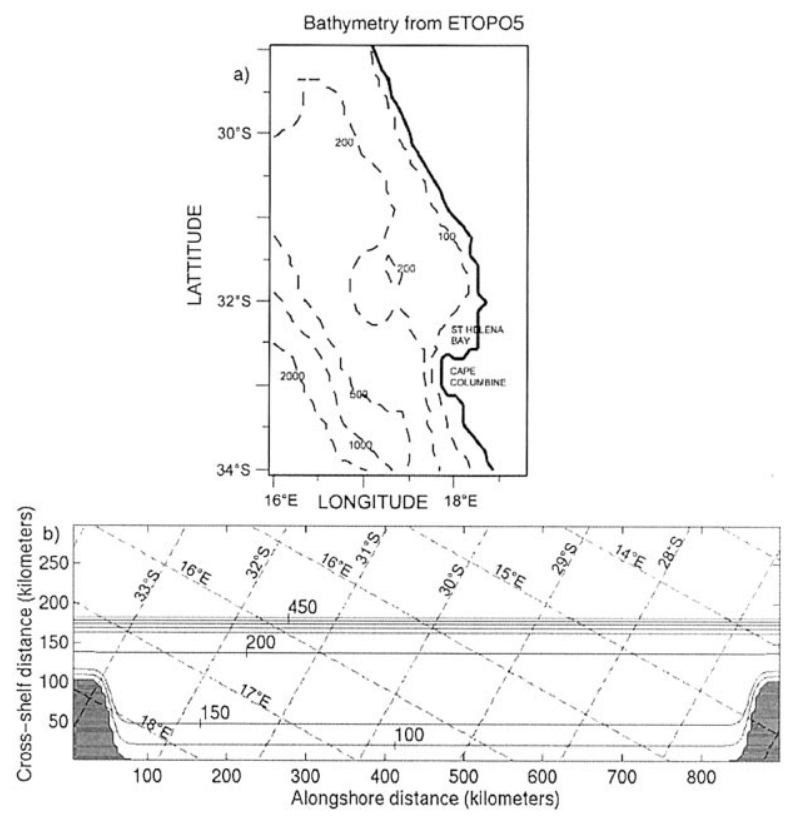

Figure 2. a) The bathymetry of the Southern Benguela derived from the ETOPO5 database. b) The periodic analytical bathymetry implemented in the model.

effects on wind around the cape and it appears to be pronounced during 'shallow southeasterly events' (marine layer thickness comparable to land elevation). Using radio tracked drifters, Holden (1985) shows that whereas the flow is predominantly northward and perturbed by small eddies, a cyclonic vortex remains in St Helena Bay and a southward current flows along the coast. Whereas stratification might be important (Bailey and Chapman, 1985), current meter moorings near Cape Columbine (Lamberth and Nelson, 1987) have demonstrated the transient barotropic nature of the flow. Offshore and associated with a subsurface front, a baroclinic jet follows the shelf edge with estimated surface velocities of $60 \mathrm{~cm} \cdot \mathrm{s}^{-1}$ (Shannon, 1985).

The outline of this paper is as follows. After a review of the interactions between coastal currents and capes, a basic description of the numerical model is provided. An analytical model of the barotropic processes gives characteristic values for velocities and free surface elevation. Outputs of a reference numerical experiment are analyzed and sensitivity tests are conducted. Finally, a tracer of the water age is integrated into the model to quantify retention.

\section{INTERACTIONS BETWEEN COASTAL CURRENTS AND CAPES}

Interactions between capes and coastal currents are complex and remain poorly understood, although they have been studied in many ways. Crepon et al. (1984) solved analytically a linear upwelling twolayer model around a rectangular promontory. Baroclinic and barotropic Kelvin waves generated at the corner of the cape propagate poleward and can lead to upwelling fluctuations independent of local winds. Further, they relate the poleward undercurrent to the difference of the phase speeds between baroclinic and barotropic waves. They found numerically the same pattern with different shapes of cape. Batteen (1997) explains the enhancement of upwelling equatorward of capes by conservation of potential vorticity in equatorward flows. Downstream and inshore of the plume of upwelled water, an "upwelling shadow" can be found, such as that described by Graham and Largier (1997) for northern Monterey Bay, where warm water is trapped at the coast behind a narrow oceanic front.

Several laboratory experiments involved flow past capes. Davies et al. (1990) introduced stratification in the case of a flat bottom and no rotation. Whereas stratification determines all aspects of eddy generation or eddy shedding from the capes, bottom friction seems to be crucial during the decay of the eddy. By introducing a counterclockwise rotation, Boyer and Tao (1987) showed that the response of the flow differs dramatically if the cape is on the left or on the right looking downstream in the northern hemisphere. Their setting corresponds to, respectively, an equatorward and poleward flow along an eastern boundary. The poleward current passes through three regimes, depending on the Burger number $\left(S=\left(N^{2} H^{2}\right) /\left(f^{2} L^{2}\right)\right.$; where $N^{2}$ is the BruntVäisälä frequency, $H$ is the water depth, $f$ is the Coriolis parameter and $L$ a characteristic length scale):

Small $S$ : flow fully attached, no eddy generated;

Medium $S$ : generation of an attached anticyclonic eddy;

Larger $S$ : shedding of anticyclonic eddies.

For the equatorward current, there is no fully attached regime: 
Small $S$ : generation of an attached cyclonic eddy (quickly formed but subsequently spins down);

Larger $S$ : shedding of cyclonic eddies.

Boyer et al. (1987) have performed the same kind of experiments with an obstacle on the left or on right of the flow, but involving this time an homogeneous fluid. They found a complex wake motion for a certain range of Rossby and Ekman parameters, and again strong differences if the cape is on the left or on the right. In the case "cape on the left", the vortex shedding is more regular, but in both cases, eddies can merge into larger structures that can be, depending of the parameters, attached, shed or advected downstream. Klinger (1993) has tested the influence of the Rossby and Ekman numbers on the formation of anticyclones on slopes, by concentrating on a barotropic flow past a corner in a rotating tank (poleward flow along an eastern boundary). In this case, whereas the gyre size is approximately proportional to the Rossby number, it is not strongly influenced by bottom friction.

Narimousa and Maxworthy (1989) have built a more realistic laboratory model to interpret satellite observations of coastal upwelling. This experiment shows the effects of ridges and capes on the generation of standing waves, meanders, filaments and eddies. The capes produce cyclones inshore and filaments offshore. These experimental results are in good agreement with satellite images of sea surface temperature off the West Coast of the North American continent. To describe the patterns measured in the lee of islands, Wolanski et al. (1984) have introduced an "Island wake parameter": $P$ from an Ekman pumping model for the control of wake eddies. This parameter can predict if friction dominates the flow $(P<1)$, if there is a stable wake $(P \sim 1)$ or if there is apparition of instabilities $(P>1)$. This result has been found to be in good agreement with the flow patterns derived from remotely sensed imagery by Pattiaratchi et al. (1986), but has been in bad agreement when the bottom topography was complex.

Similar studies have been conducted using numerical models. Becker (1991) built a numerical model of a viscous flow past a cylinder in a rotating frame, when the Rossby $(R o)$ and the Ekman $(E k)$ numbers are small. She found two key parameters for the boundary layer separation: $\lambda=R o /(2 \sqrt{E k})$, which is an equivalent of the "Island wake parameter" and $\delta$ is the boundary layer thickness. The flow starts to detach when $\lambda>1$, and the bubble length increases linearly with $\lambda$ and with decreasing $\delta$. The generation and evolution of eddies around headlands by a tidal flow have been studied analytically and numerically by Signell and Geyer (1991). In a boundary layer model, detachment occurs because of bottom friction as soon as an adverse pressure gradient is established. They found using a 2D numerical model that the extent of vorticity is limited by the frictional length scale: $l_{f}=H /\left(2 C_{D}\right)$. In a two layer realistic numerical model of Oregon coast, Peffley and O'Brien (1975) showed that bottom topography overwhelms coastline irregularities in the generation of mesoscale upwelling features. On the contrary, using a realistic 3D numerical model of the California upwelling system, Batteen (1997) found that wind forcing and coastline irregularities are key mechanisms for the generation of meanders, eddies, jets and filaments. She showed that capes 'anchor' filaments and generate cyclonic eddies. The process of generation and control of a cyclonic eddy past Point Conception has been studied by Oey (1996). In a one and a half layer, reduced gravity model (infinite bottom layer), equatorward wind forced currents generate a cyclonic eddy past the cape by advection of vorticity at the corner. Viscosity and the Rossby number control it. This eddy is found again in a 3D realistic model of the Santa Barbara Channel. It seems to follow the same processes of formation, although bottom topography and beta effect are shown to become important for longer time period ( $>30$ days).

A main discrepancy between our study and Oey's work (Oey, 1996) is the width of the shelf in St Helena Bay that extends from $50 \mathrm{~km}$ to $150 \mathrm{~km}$, while the extension of the shelf in front of Point Conception is limited to $20 \mathrm{~km}$. The presence of those shallow waters invalidate the use of a one and a half layer, reduced gravity model, and bottom effects should be important in the generation and control of cyclonic eddies. It appears then that the presence and the shape of the bottom topography should overwhelm the effects related to stratification. To quantify this, the Brunt-Väisälä frequency $N^{2}$ has been calculated using recent temperature and salinity measurements in the bay. It has a typical value of $7 \times 10^{-3}$ $\mathrm{s}^{-1}$. Whereas stratification is significant, the gentle 
bottom slope of St Helena Bay (slope coefficient: $\alpha \sim 0.2 \%$ ) satisfies the dynamic criterion for barotropic shelf water response (Clark and Brink, 1985): $\left(N^{2} \alpha^{2}\right) / f^{2} \ll 1$ where $f$ is the Coriolis parameter. In St Helena Bay, $\left(N^{2} \alpha^{2}\right) / f^{2} \sim 0.05$. This 'bottom slope' Burger number allows us to state that whereas density related processes, as upwelling and associated baroclinic coastal jets, might be important, most of the circulation can be described by barotropic dynamics. This is consistent with the barotropic nature of the flow measured by Lamberth and Nelson (1987). However, stratification may be an important factor in its effects on vertical eddy viscosities and therefore the influence of bottom friction on the water column.

In this work, we will only concentrate on the barotropic response of a coastal ocean to an equatorward wind forcing. Baroclinic effects are expected to be secondary or localized (Graham and Largier, 1997) and will be investigated in future work. The aim of this paper is to understand the processes controlling the pattern of flow detachment and eddy generation in the vicinity of Cape Columbine.

\section{MODEL DESCRIPTION}

The numerical code is the barotropic part of the SCRUM oceanic model from Rutgers University (Song and Haidvogel, 1994; Hedström, 1997). The model is based on the hydrostatic and Boussinesq approximations. The barotropic component solves the vertically integrated momentum equation (Hedström, 1997) and in our case density variations are not taken into account. SCRUM conserves the first moments of $u$ and $v$. This is accomplished by using the flux form of the momentum equations (Hedström, 1997):

$$
\begin{aligned}
& \frac{\partial}{\partial t}(D \bar{u})+\frac{\partial}{\partial x}(D \bar{u} \bar{u})+\frac{\partial}{\partial y}(D \bar{u} \bar{v})-D f \bar{u} \\
& =-g \frac{\partial}{\partial x}(D \zeta)+v_{4} \hat{\Delta}\left(\frac{\hat{\Delta}(\bar{u})}{D}\right)+\frac{\tau_{x}}{\rho}-r \bar{u} \\
& \frac{\partial}{\partial t}(D \bar{v})+\frac{\partial}{\partial x}(D \bar{u} \bar{v})+\frac{\partial}{\partial y}(D \bar{v} \bar{v})+D f \bar{v} \\
& =-g \frac{\partial}{\partial y}(D \zeta)+v_{4} \hat{\Delta}\left(\frac{\hat{\Delta}(\bar{v})}{D}\right)+\frac{\tau_{y}}{\rho}-r \bar{v}
\end{aligned}
$$

where $\hat{\Delta}$ is the operator:

$$
\hat{\Delta}(A)=\frac{\partial}{\partial x} D \frac{\partial A}{\partial x}+\frac{\partial}{\partial y} D \frac{\partial A}{\partial y}
$$

The continuity equation takes the form:

$\frac{\partial \zeta}{\partial t}+\frac{\partial}{\partial x}(D \bar{u})+\frac{\partial}{\partial y}(D \bar{v})=0$

where:

$x$ is the alongshore coordinate (positive towards the equator).

$y$ is the cross-shore coordinate (positive towards the open ocean).

$\bar{u}$ and $\bar{v}$ are the vertically averaged flow velocity respectively in each coordinate direction.

$\zeta$ is the free surface elevation.

$D$ is the total water column depth, $D=H+\zeta$, where $H$ is the ocean depth.

$f$ is the Coriolis parameter, $f=2 \Omega \sin \phi$, where $\Omega$ is the Earth angular velocity and $\phi$ is the latitude. In our case, because the time scale $O(10$ days $)$ and the length scales $O(100 \mathrm{~km})$ are small enough, we can assume a constant Coriolis parameter as explained by Kundu (1990). $f=-7.707 \times 10^{-5} \mathrm{~s}^{-1}$ at Cape Columbine.

$g$ is the Earth gravity acceleration, $g=9.81 \mathrm{~m} . \mathrm{s}^{-2}$.

$v_{4}$ is the lateral biharmonic constant mixing coefficient $\left(\mathrm{m}^{4} \cdot \mathrm{s}^{-2}\right)$.

$r$ is the linear bottom drag coefficient $\left(\mathrm{m} . \mathrm{s}^{-1}\right)$.

$\tau_{x} / \rho$ and $\tau_{y} / \rho$ are the kinematic surface momentum fluxes (wind stress) respectively in each coordinate direction $\left(\mathrm{m}^{2} \cdot \mathrm{s}^{-2}\right)$.

In order to preserve the mesoscale structures, a biharmonic operator parameterizes the horizontal viscosity. For the sake of simplicity and as suggested by Csanady (1982), the weak tidal currents are not resolved and the bottom stress is chosen to be proportional to the barotropic velocities. The linear bottom friction coefficient is initially fixed at a typical value found in the literature $\left(r=3 \times 10^{-4} \mathrm{~m} . \mathrm{s}^{-1}\right)$, but sensitivity tests have been conducted to explore the strong impact of this coefficient on the circulation.

The regular grid has a $5 \mathrm{~km}$ resolution alongshore and cross-shore. The coastline is represented by a free-slip wall in $x=0$ and its variations are modelized by masking the inshore grid points where the depth is less than $50 \mathrm{~m}$ (Hedström, 1997). The most straightforward way to close the domain offshore and on the 
sides is the use of a periodical channel: a free-slip wall far beyond the shelf break and all the outflows (inflows) at the southern boundary are inflows (outflows) for the northern boundary. Those boundary conditions allow an alongshore wind forced circulation and conserve mass. The presence of the shelf break should insulate the shelf circulation from the effects of the offshore wall (Csanady, 1978). The bottom topography is represented by a set of analytical functions which retains the main topographical features, thus focusing attention on the effects of Cape Columbine and the widening shelf on the circulation. The bathymetry has been made periodic to allow the use of the periodic channel (figure $2 b$ ). The second cape on the right might perturb the solution at distances up to $300 \mathrm{~km}$ (the external Rossby radius) upwind of the cape, thus interfering with our area of interest. For this reason, the experiments are run with an alongshore domain as long as $900 \mathrm{~km}$. The atmospheric forcing is a constant wind stress parallel to the $x$-axis, accounting for the summer southeastern wind. The wind stress is uniform in space and constant in time for a given experiment. A set of runs with wind stress ranging from $0.02 \mathrm{~N} . \mathrm{m}^{-2}$ to $0.2 \mathrm{~N} . \mathrm{m}^{-2}$ are performed to investigate the effects of the intensity of the wind forcing.

\section{ANALYTICAL EXPECTATIONS}

To illustrate the basic mechanism for wind driving in the coastal ocean, Brink (1998) solved a linearized alongshore wind forced model, where the spatial scales are small enough compared to the external Rossby radius of deformation to neglect divergence, and where the alongshore scales are large compared to the cross-shore ones (boundary layer approximation; Csanady, 1998). This implies that the alongshore flows are much stronger than the cross-shelf ones (Brink, 1998). This is not true near Cape Columbine, but it can be a good approximation further North. Thus, the results from this model can give us a scale for the mean alongshore velocities and the sea surface slope to compare with the numerical experiment outputs. If the wind forcing is uniform, the alongshore variations can be neglected and the barotropic equations of motion with linear bottom friction become (Brink, 1998; Csanady, 1998), using the same notations as in the previous paragraph: $\frac{\partial \bar{u}}{\partial t}-f \bar{v}=\frac{\tau_{x}}{H \rho}-\frac{r \bar{u}}{H}$

$f \bar{u}=-g \frac{\partial \zeta}{\partial y}$

$\frac{\partial H \bar{v}}{\partial y}=0$

The alongshore velocities are forced by the alongshore wind and the free surface remains in geostrophic equilibrium with the alongshore velocities. In order to satisfy equation (7) and the fact that there is no cross-shore flow at the coastal boundary, the cross-shelf transport has to vanish everywhere (Brink, 1998). Starting from rest at $t=0$ with a constant wind stress, we obtain from equation (5):

$\bar{u}=\frac{\tau_{x}}{\rho r}\left(1-e^{-\frac{r t}{H}}\right)$

If the maximum depth is $500 \mathrm{~m}$, the solution is nearly stationary after 40 days with alongshore velocities:

$\bar{u}=\frac{\tau_{x}}{\rho r}$

Those results show that bottom friction allows us to expect for the numerical experiments a steady solution after nearly 50 days with alongshore velocities of the order of magnitude: $O\left(\tau_{x} / \rho r\right)$. For example, if the wind stress value equal $1 \times 10^{-2} \mathrm{~N} \cdot \mathrm{m}^{-2}$, after 50 days the mean alongshore velocities should be $O(0.28) \mathrm{m} . \mathrm{s}^{-1}$.

\section{THE REFERENCE EXPERIMENT}

To avoid the spurious effects of the periodic channel, like the perturbations caused by the artificial cape at the right side of the domain, we have chosen to run the reference experiment on a wide domain $(900 \mathrm{~km}$ alongshore). The constant wind stress value is fixed at $0.1 \mathrm{~N} . \mathrm{m}^{-2}$ corresponding to the average wind stress measured in the area during upwelling seasons $\left(\sim 0.098 \mathrm{~N} . \mathrm{m}^{-2}\right)$. The linear bottom friction coefficient value is $3 \times 10^{-4} \mathrm{~m} \cdot \mathrm{s}^{-1}$ and the viscosity parameter is set to the lowest possible value to avoid numerical noise $\left(1.5 \times 10^{9} \mathrm{~m}^{4} \mathrm{~s}^{-1}\right)$.

Starting from rest, an equatorward current develops in response to the equatorward wind forcing. In balance with the alongshore velocities, a cross shelf slope of the free surface is set up (figure $3 a-c$ ). The 
solution becomes steady after 50 days (figure 3c), the average sea surface slope value is between 0.17 and 0.38 centimeters per kilometer and the mean alongshore velocities are approximately equal to 0.28 $\mathrm{m} . \mathrm{s}^{-1}$.

Although the presence of a coastline and bottom topography variations induces a drag that reduces the alongshore velocity, its value stays in the same order of magnitude as in the analytical solution. Four scaling parameters allow us to compare the results with other studies:

1. The Rossby number,

$R o=\frac{\text { advection }}{\text { Coriolis }}=\frac{U}{|f| L}$

2. Because of the use of a biharmonic operator, the Reynolds number takes the form:

$R e_{\text {biharm }}=\frac{\text { advection }}{\text { viscosity }}=\frac{U L^{3}}{v_{4}}$
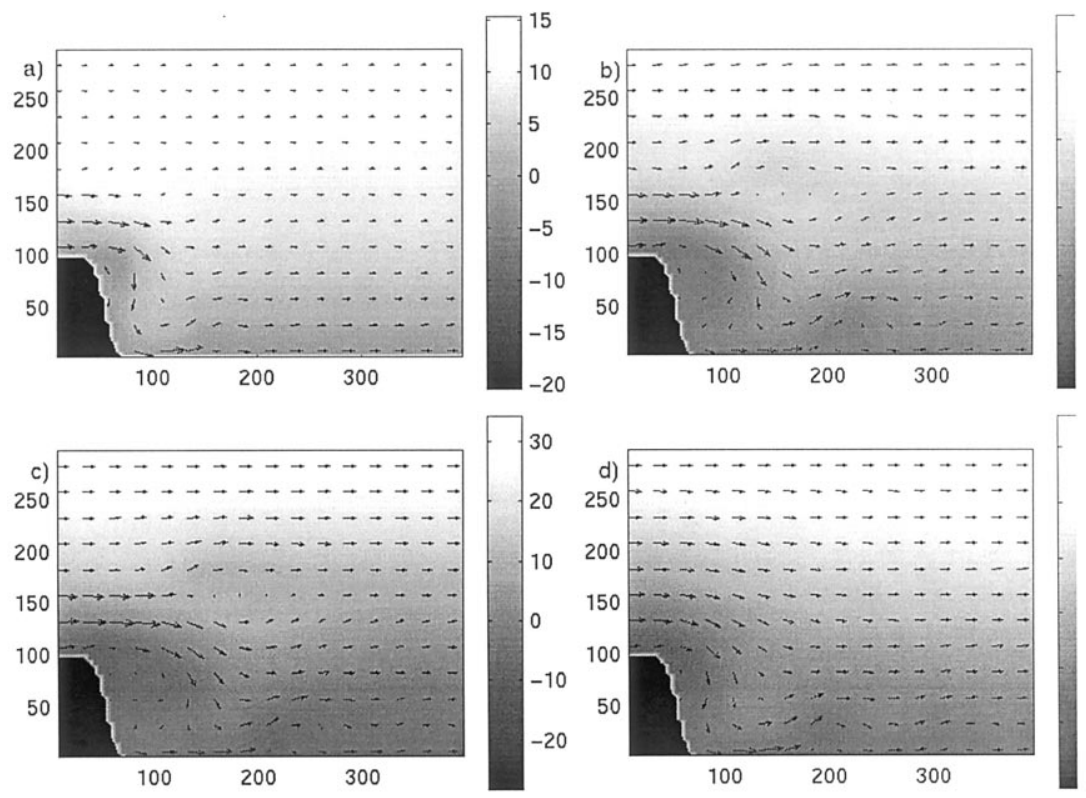

Figure 3. Barotropic velocities and free surface elevation for the reference experiment in the vicinity of Cape Columbine: a) day 10 (maximum velocity: $62 \mathrm{~cm} . \mathrm{s}^{-1}$, averaged velocity: $16 \mathrm{~cm} . \mathrm{s}^{-1}$ ), b) day 30 (maximum velocity: $69 \mathrm{~cm} . \mathrm{s}^{-1}$, averaged velocity: $25 \mathrm{~cm} . \mathrm{s}^{-1}$ ), c) day 50 (maximum velocity: $70 \mathrm{~cm} \cdot \mathrm{s}^{-1}$, averaged velocity: $28 \mathrm{~cm} \cdot \mathrm{s}^{-1}$ ), d) day 50 for the same experiment with no shelf-edge (maximum velocity: $71 \mathrm{~cm} \cdot \mathrm{s}^{-1}$, averaged velocity: $30 \mathrm{~cm} \cdot \mathrm{s}^{-1}$ ). The horizontal coordinates are in kilometers and the gray scale range for the free surface elevation is in centimeters. 
From these values we obtain: $R o=3.6 \times 10^{-2}$, $R e_{\text {biharm }}=1.9 \times 10^{5}, \quad R e_{\text {friction }}=1.4$ and $E k=2.6 \times$ $10^{-2}$. Hence, Coriolis acceleration and the resultant pressure gradient are the main driving forces and at the first order, advection and bottom friction are the two important terms controlling the flow. Further, those terms show that this experiment is in the attached-cyclonic-eddy regime [small Rossby number, small Burger number (null in our case)] when the cape is on the left (in the Northern Hemisphere) as in the study of Boyer and Tao (1987). $R e_{\text {friction }}=O(1)$ shows that this regime corresponds to the stable wake regime of Wolanski et al. (1984). $\lambda=1.4$ and $\delta=$ $5.2 \times 10^{-2}$ are at the limit between the detachment and the no-detachment regime of Becker (1991). The small Rossby and Ekman numbers correspond to the stable wake regime described by Boyer et al. (1987).

The reference experiment shows that the bottom topography associated with Cape Columbine generates three main features:

1. Attached cyclonic eddy: before day 10, the flow detaches from Cape Columbine and generates an attached cyclonic eddy (figure $3 a, x=50 \mathrm{~km}, y=$ $100 \mathrm{~km}$ ). The size of the eddy is approximately 60 $\mathrm{km}$ at day 10 and expands to a size of $110 \mathrm{~km}$ by day 50 (figure $3 a, b$ and $c$ ). The presence of this stationary attached-cyclonic-eddy is in qualitative agreement with the in-situ measurements of Holden (1985) and with the experimental results of Boyer and Tao (1987) [for the cape on the left (Northern Hemisphere), the smallest Burger number and $R o=O(0.02)]$. Further, the presence of the cyclone and the strength of the velocities match the results of the 3D model of Oey (see figures 12 and 13 in Oey, 1996). In the Santa Barbara Channel model, which includes baroclinic processes, Oey (1996) applied an equatorward wind stress similar to the forcing of the reference experiment. The bottom fiction is quadratic $\left(C_{d}=\right.$ $\left.2.5 \times 10^{-3}\right)$ and the grid resolution is $5 / 3 \mathrm{~km}$. The equatorward flow associated with a pronounced coastal upwelling is in agreement with the barotropic velocities obtained here, and forms a sta- tionary cyclonic eddy in the lee of Point Conception (see 12 and 13 in Oey, 1996). The size of this eddy is approximately half the size of our barotropic eddy. This discrepancy might be due to the depth of the shelf $(300 \mathrm{~m}$ versus $150 \mathrm{~m}$ in our experiment $)$, the width of the shelf $(50 \mathrm{~km}$ versus $150 \mathrm{~km}$ in our experiment) or the presence of the Santa Barbara islands that block the cyclone extension.

2. Influence of the shelf break: the steep shelf edge offshore (figure $2 b, y=150 \mathrm{~km}$ ) applies a strong topographic constraint on the flow, prohibiting cross-topographic currents. Thus, mass conservation implies that the velocities between Cape Columbine and the shelf break (figure $3 a-c$, for $x=0 \mathrm{~km}$ and $y=0$ to $150 \mathrm{~km}$ ) are stronger than in the other parts of the shelf. This can affect the detachment process. An experiment with no shelf break (figure $3 d$ ) shows that at day 50, the size of the cyclonic eddy is approximately $60 \%$ of the size of the eddy in the reference experiment. The value of the alongshore velocities near the tip of the cape is $80 \%$ of the value of the velocities in the reference experiment. Furthermore, vortex squashing produces an anticyclonic bend on the shelf edge (figure $3 c, x=180 \mathrm{~km}, y=150 \mathrm{~km}$ ) and a divide in the currents (figure $3 c, x=110 \mathrm{~km}$, $y=150 \mathrm{~km})$. Its location corresponds approximately to the location of the Columbine divide described by Shannon (1985), and it can be an explanation of this phenomenon.

3. Upstream blocking: the artificial cape on the right seems to have no influence on the detachment processes, but it produces weak near shore velocities on the right of the shelf (figure not shown). This effect can be felt up to $300 \mathrm{~km}$ [O(external Rossby radius of deformation)] upstream of the cape. Because we use a large domain $(900 \mathrm{~km}$ alongshore), this phenomenon does not affect our area of interest. This has been tested using a smaller domain (600 km alongshore) and the similarities between the solutions validate the use of the periodic channel.

Figure 4. Accelerations $\left(\mathrm{m} . \mathrm{s}^{-2}\right.$ ) applied to the water particles for the reference experiment at day 50 (the contours represent the free surface elevation in decimeters). a) At zero order, the balance between pressure gradient and Coriolis acceleration dominates the dynamics. b) First order tendency terms: by summing the pressure gradient and the Coriolis acceleration, the zero order balance can be filtered out and the first order terms can be studied. Note that this terms are 20 times smaller than the zero order ones. 
a) Zero order terms

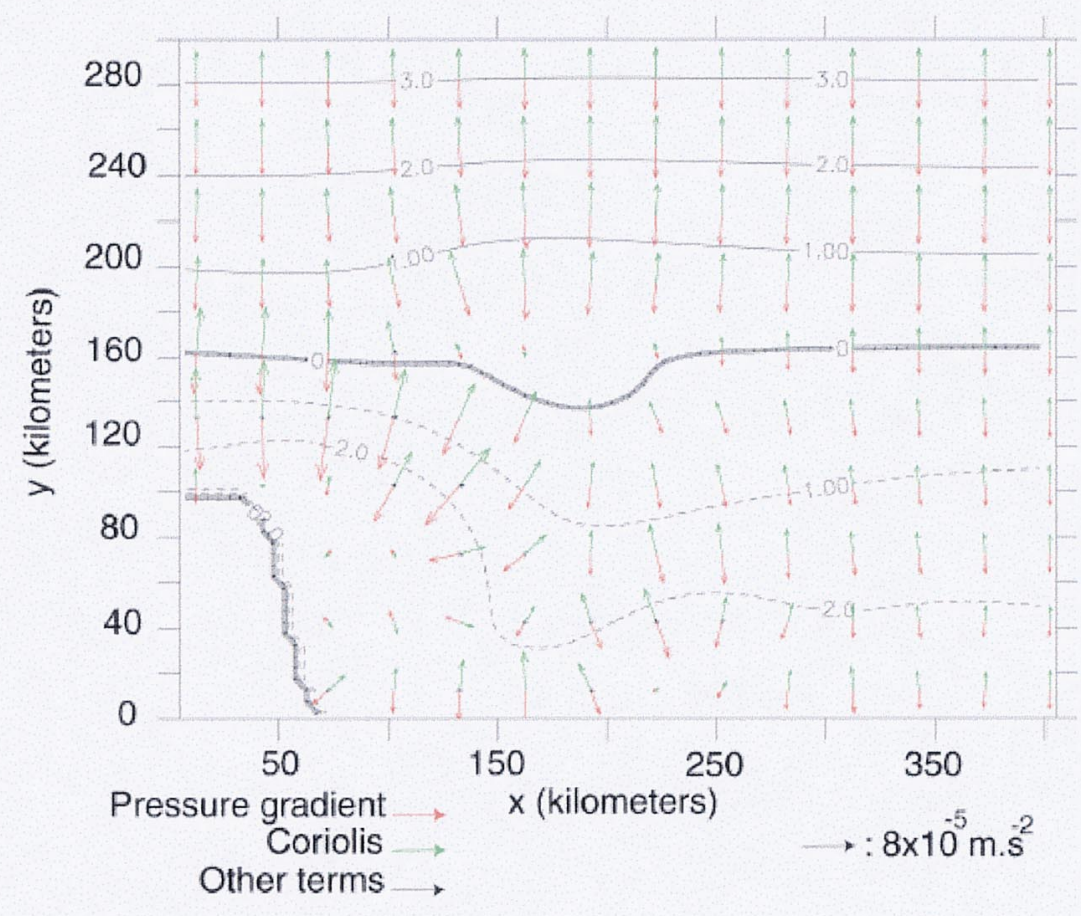

b) First order terms

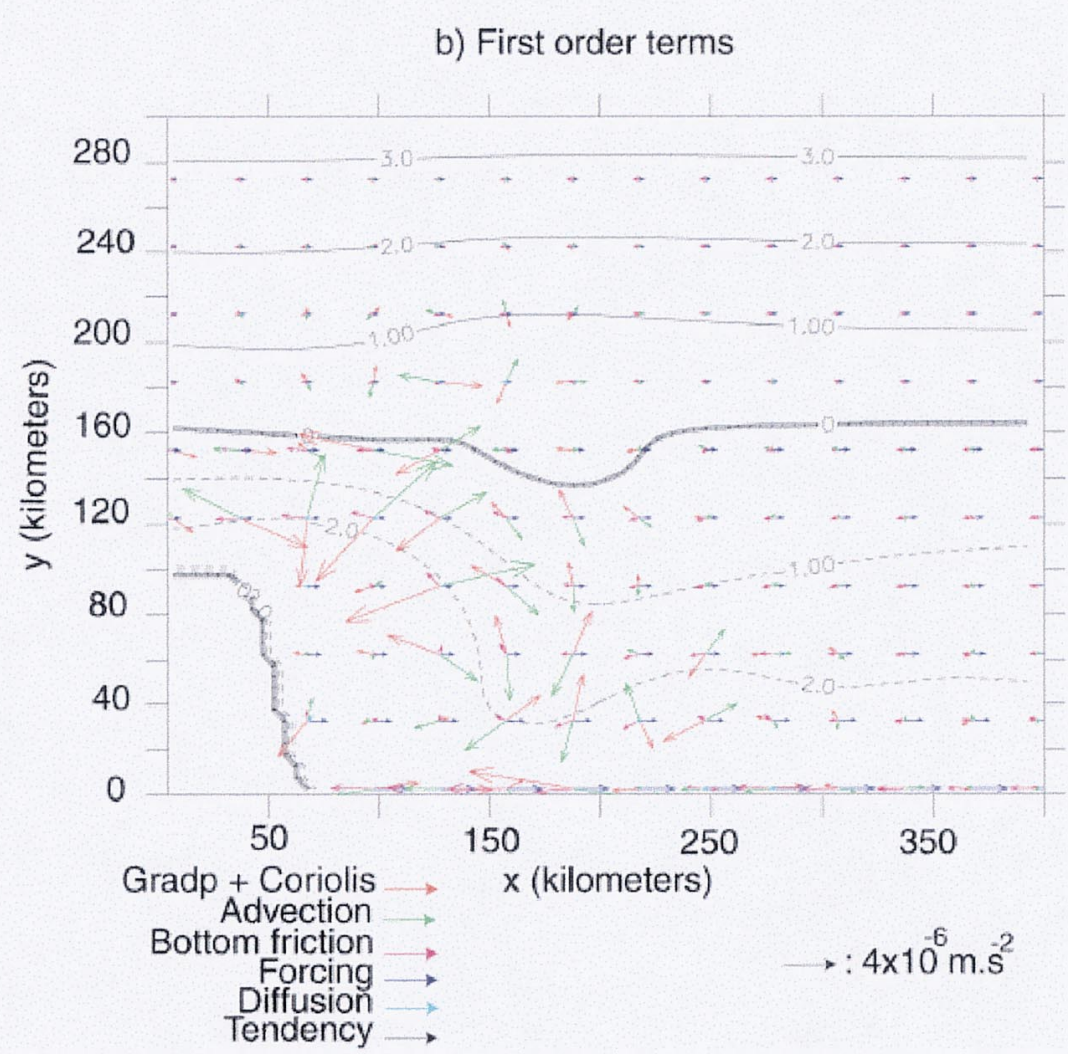

Fig. 4. 


\section{DIAGNOSTIC ANALYSIS}

\subsection{Dynamical balance}

To understand the processes involved in the cyclone generation, the dynamical terms have been computed from the model outputs using equations (1) and (2). They have been rewritten in the form of a sum of acceleration vectors as follows:

$$
\underbrace{\frac{1}{D} \frac{\partial D \overrightarrow{\bar{u}}}{\partial t}}_{\overline{\text { Tendency }}}=\underbrace{-\frac{1}{D}[\nabla \cdot(D \overrightarrow{\bar{u}})]}_{\overrightarrow{\text { Advection }}} \underbrace{\overrightarrow{\bar{u}}-f \vec{k} \wedge \overrightarrow{\bar{u}}}_{\text {Coriolis }}-\underbrace{\frac{g}{D} \nabla(D \zeta)}_{\text {GradP }} \underbrace{\frac{v_{4}}{D} \hat{\Delta} \frac{\hat{\Delta} \overrightarrow{\bar{u}}}{D}}_{\overrightarrow{\text { Viscosity }}}-\underbrace{\frac{\overrightarrow{\vec{u}}}{D}}_{\text {Friction }}+\frac{\vec{\tau}}{\rho D}
$$

where $\overrightarrow{\vec{u}}$ is the vertically averaged flow velocity, $\vec{\tau}$ is the wind stress and $\vec{k}$ is a vertical unit vector. Because $\zeta / H \sim O\left(10^{-3}\right) \ll 1$ and $\left({ }^{\partial D} / \partial x\right) / D \sim O\left(10^{-5}\right) \ll 1$, the terms of equation (14) are respectively equivalent to the terms of the vertically averaged momentum equation:

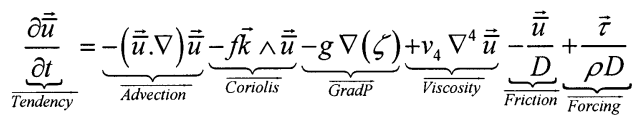

It appears (figure 4a) that at zero order, the balance between pressure gradient and Coriolis acceleration overwhelms the other accelerations. This is in agreement with the small Rossby and Ekman numbers found previously. The Coriolis acceleration pushes the flow offshore, creating an Ekman transport away from the coast, in agreement with the upwelling models. Because of mass conservation, this transport produces a down slope toward the coast in the free surface, generating a pressure gradient in balance with the Coriolis acceleration (Csanady, 1982).

By summing the pressure gradient vectors and the Coriolis acceleration vectors, we can filter out the zero order balance and get the equilibrium at the first order [figure $4 b$, note that these accelerations are 20 times smaller than in figure $4 a$, in agreement with $R o$ and $\left.E k \sim O\left(10^{-2}\right)\right]$. At this order, most of the terms start to be important. In the following, we call the sum of the pressure gradient and the Coriolis acceleration the ageostrophic pressure gradient.
1. Viscous terms are of an order of magnitude lower than the other ones. They have some relative importance near the tip of the cape (figure $4 b$, $x=40 \mathrm{~km}, y=100 \mathrm{~km}$ ) and in the corner of the bay (figure $4 b, x=60 \mathrm{~km}, y=10 \mathrm{~km}$ ). As explained by Becker (1991), viscosity has to be small for detachment to occur.

2. Around the external part of the eddy (figure $4 b$, $x=50$ to $130 \mathrm{~km}, y=70$ to $130 \mathrm{~km}$ ), there is a competition between advection and ageostrophic pressure gradient. It appears that around the eddy (figure $4 b, x=140 \mathrm{~km}, y=100 \mathrm{~km}$ ), the radius of curvature of the flow is approximately $R=85 \mathrm{~km}$ and the tangential velocities are about $V=0.5$ $\mathrm{m} . \mathrm{s}^{-1}$. Then the normal acceleration is $\gamma=\left(V^{2}\right)$ $R) \simeq 2.9 \times 10^{-6} \mathrm{~m} . \mathrm{s}^{-2}$, which is not very far from the value of this advective acceleration $(\simeq 3.4 \times$ $10^{-6} \mathrm{~m} \cdot \mathrm{s}^{-2}$ ). This enlights a cyclo-geostrophic equilibrium around the eddy. This advective acceleration seems to be responsible for the detachment.

3. Away from perturbations (figure $4 b$, for example $y>220 \mathrm{~km}$ ), the wind forcing and bottom friction relative equilibrium controls the alongshore velocities as in the analytical solution.

4. Another equilibrium occurs where the velocities are weak: inside the eddy (figure $4 b, x=75 \mathrm{~km}$, $y=70 \mathrm{~km})$ and in the upstream blocking area $(x=650$ to $850 \mathrm{~km}, y=0$ to $60 \mathrm{~km}$, figure not shown). In those places the Coriolis acceleration is weak and a static wind stress-pressure gradient balance prevails.

\subsection{Vorticity balance}

To refine the study, curls of the acceleration vectors fields extracted from equation (14) are computed to obtain the terms of the equation for the vertically averaged vertical component of vorticity, $\bar{\xi}$. Their physical "meaning" can be illustrated (equation (16)) by deriving the curl of equation (15) and introducing the continuity equation (4):

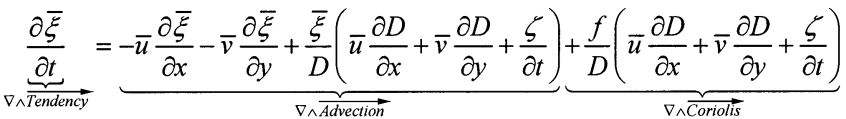

$$
\begin{aligned}
& \underbrace{+v_{4}\left(\frac{\partial^{4} \bar{\xi}}{\partial x^{4}}+\frac{\partial^{4} \bar{\xi}}{\partial y^{4}}\right)}_{\nabla \wedge \text { Viscosity }} \underbrace{-\frac{r \bar{\xi}}{D}+\frac{r}{D^{2}}\left(v \frac{\partial D}{\partial x}-u \frac{\partial D}{\partial y}\right)}_{\nabla \wedge \text { Frecion }} \underbrace{+\frac{1}{\rho D}\left(\frac{\partial \tau_{y}}{\partial x}-\frac{\partial \tau_{x}}{\partial y}\right)-\frac{1}{\rho D^{2}}\left(\tau_{y} \frac{\partial D}{\partial x}-\tau_{x} \frac{\partial D}{\partial y}\right)}_{\nabla_{\wedge} \text { Forceng }}
\end{aligned}
$$


- $\nabla \wedge$ Advection is the advection of vorticity added to the vortex stretching associated with relative vorticity.

- $\nabla \wedge$ Coriolis is the vortex stretching associated with planetary vorticity. Because the Rossby number is small, this term is much larger (10 to 100 times) than the vortex stretching associated with relative vorticity.

- As explained by Signell and Geyer (1991), the first term of $\nabla \wedge$ Friction is the vorticity dissipation by bottom friction and the second one is the slope torque' which acts as a source of vorticity when there is a component of velocity normal to the depth gradient. These two terms are in the same order of magnitude. Because $R e_{\text {friction }}=O(1)$, the curl of bottom friction should be in the same order of magnitude as the advection of vorticity.

- The first term of $\nabla \wedge$ Forcing is the Ekman pumping associated with the wind stress curl and the second term is by analogy with the 'friction slope torque', a 'wind stress slope torque' which can be a source of vorticity when the wind is normal to the depth gradient. In our case, for $\tau_{y}=0$ and $\tau_{x}=0.1 \mathrm{~N} \cdot \mathrm{m}^{-2}$, the order of magnitude of the ratio between 'wind stress slope torque' and advection of vorticity is:

$\frac{\tau_{x} L}{\rho H U^{2}} \sim 1.4$

Then, this term can not be neglected. Its effects can be illustrated by tacking the curl of the analytical solution for the velocities (equation (8)). During the spin-up, because $H$ is a function of $y, \bar{u}$ is also a function of $y$. Thus the vorticity is:

$$
\bar{\xi}=-\frac{\partial \bar{u}}{\partial y}=\frac{\tau_{x} \frac{\partial \bar{u}}{\partial y}}{\rho H^{2}} e^{-\frac{r t}{H}}
$$

In this case, the vorticity produced continually since the beginning of the experiment by the "wind stress slope torque, is progressively dissipated by bottom friction and 'friction slope torque'. Thus, after 50 days, the stationary solution is irrotational. In the same manner as the 'friction slope torque', the 'wind stress slope torque' appears because surface and bottom stresses have both a
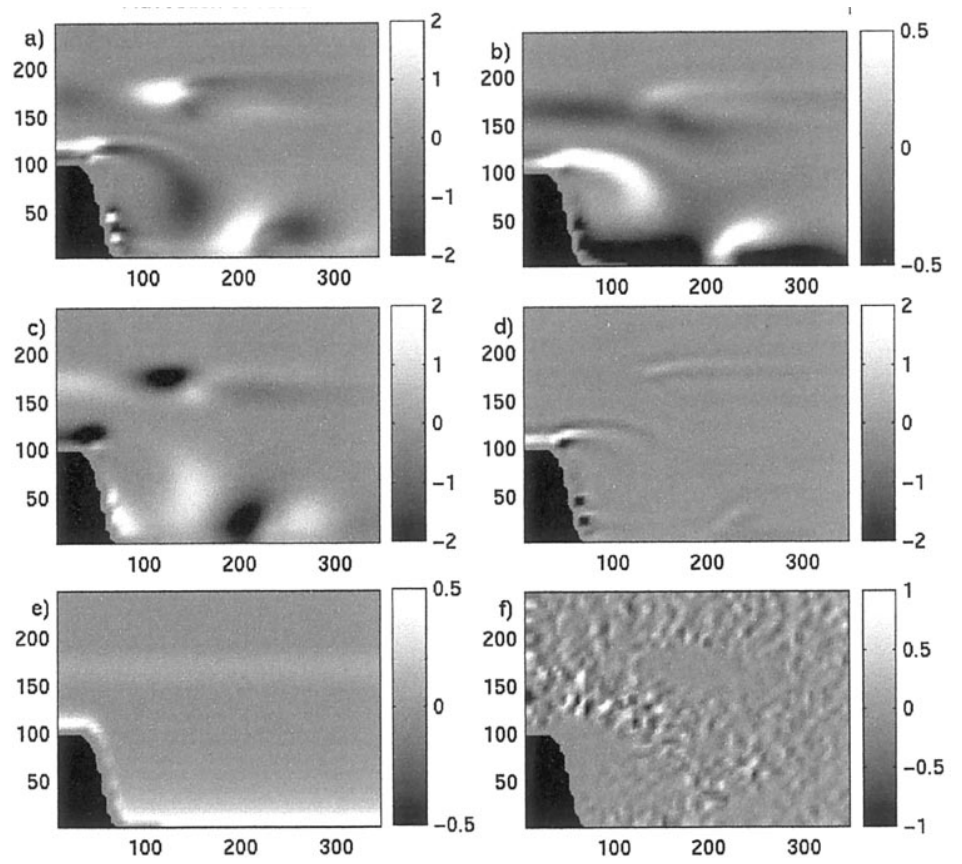

Figure 5. Tendency terms of the vorticity equation $\left(\mathrm{s}^{-2}\right)$, computed from the dynamical terms at day 50 for the reference experiment: a) advection of vorticity, b) curl of bottom friction, c) vortex stretching, d) lateral viscous dissipation, e) wind stress slope torque, f) curl of the pressure gradient. The horizontal coordinates are in kilometers and the gray scale range shows the terms values in $\mathrm{s}^{-2}$, multiplied by $10^{-10}$, except for the values of curl of the pressure gradient which are multiplied by $10^{-24}(\mathrm{f})$. 
stronger effect in shallow waters than in deep waters.

Figure 5 exhibits the relative importance of the vorticity equation terms in the vicinity of Cape Columbine. The advection of vorticity (figure $5 a$ ) contains as well the vortex stretching associated with relative vorticity, but this term is one order of magnitude smaller than the other terms. The curl of bottom friction (figure $5 b$ ) contains both the bottom dissipation and the 'friction slope torque' and is thus not proportional to relative vorticity in shallow waters. The vortex stretching (figure 5c) is the vortex stretching associated with planetary vorticity. The unit of those terms is $\mathrm{s}^{-2}$ and for clarity the values have been multiplied by $10^{10}$ (figure $5 a-e$ ). To validate the approximations made in deriving the tendancy terms, the curl of the pressure gradient has been plotted as well, multiplied by $10^{24}$ (figure $5 f$ ).

We can then extract different equilibriums:

1. The balance between advection of vorticity and vortex stretching occurs almost everywhere the slopes are strong: on the shelf break (figure $5 a$ and $c, y=150$ to $200 \mathrm{~km}$ ) and in the bay (figure $5 a$ and $c, y=0$ to $60 \mathrm{~km}$ )

2. Around the external part of the eddy, where the shelf is relatively flat and the dynamic is cyclogeostrophic (see previous section), the curl of bottom friction balances the advection of vorticity (figure $5 a$ and $b, x=50$ to $130 \mathrm{~km}, y=70$ to 130 $\mathrm{km})$. This balance seems to follow the contour of the eddy, and might control its extension.

3. As pointed out in the previous section, the lateral viscosity has some importance near the tip of Cape Columbine. In figure $5 d$, the viscous boundary layer is clearly seen for $x=0$ to $50 \mathrm{~km}$ and $y=100$ to $110 \mathrm{~km}$. Past the cape, there is a detachment of this boundary layer (figure $5 d, x=$ 50 to $80 \mathrm{~km}, y=115 \mathrm{~km}$ ).

4. In shallow waters, the friction and wind stress slope torques start to have a strong importance and seem to be in balance for $x>80 \mathrm{~km}$ and $y=0$ to $10 \mathrm{~km}$ (figure $5 b$ and $e$ ).

We can expect from the second point that the size of the eddy is controlled by the balance between advection of vorticity and curl of bottom friction. From this, we can extract a characteristic length scale $l$ :
$\frac{H U^{2}}{l^{2}}$ (advection of vorticity)

$\sim \frac{r U}{l}$ (curl of bottom friction)

$\Rightarrow l \sim \frac{H U}{r}$

This length scale can be seen as a frictional e-folding distance and is equivalent to the eddy length scale $R_{l}$ described by Pattiaratchi et al. (1986) and Wolanski et al. (1984). It is equivalent to the frictional length scale $l_{f}$ tested by Signell and Geyer (1991).

Taking the analytical result (equation 9) for the characteristic velocities, equation (20) becomes:

$l \sim \frac{H \tau}{\rho r^{2}}$

That gives us a characteristic eddy length scale which is a function of the wind stress and of the linear bottom friction parameter. This length scale can be compared to the size of the eddy. In this example, $H=150 \mathrm{~m}, \tau / \rho=10^{-4} \mathrm{~m}^{2} . \mathrm{s}^{-2}$, and $r=3 \times 10^{-4}$ $\mathrm{m} . \mathrm{s}^{-1}$ so that $l=167 \mathrm{~km}$ (the difference with the model outputs can be seen in figure 3).

\section{SENSITIVITY TESTS}

To test the effects of the surface wind stress, the bottom friction coefficient, the grid resolution, the viscosity coefficient and the domain size on recirculation processes, several numerical experiments are conducted by varying one parameter at a time. Within realistic parameter values, the grid resolution and the viscosity do not have much effect on the cyclone generation. However, the nature of the cyclone does depend on bottom friction and wind.

\subsection{Influence of the wind stress}

Using the same parameters as the reference experiment, ten experiments are run with different alongshore wind stress values, varying from $0.02 \mathrm{~N} . \mathrm{m}^{-2}$ to $0.2 \mathrm{~N} . \mathrm{m}^{-2}$. These wind stress values correspond to wind velocities of about $4 \mathrm{~m} . \mathrm{s}^{-1}$ to $11 \mathrm{~m} . \mathrm{s}^{-1}(10 \mathrm{~m}$ elevation). In all cases, the solution is steady at day 50 and the order of magnitude of the mean velocities 

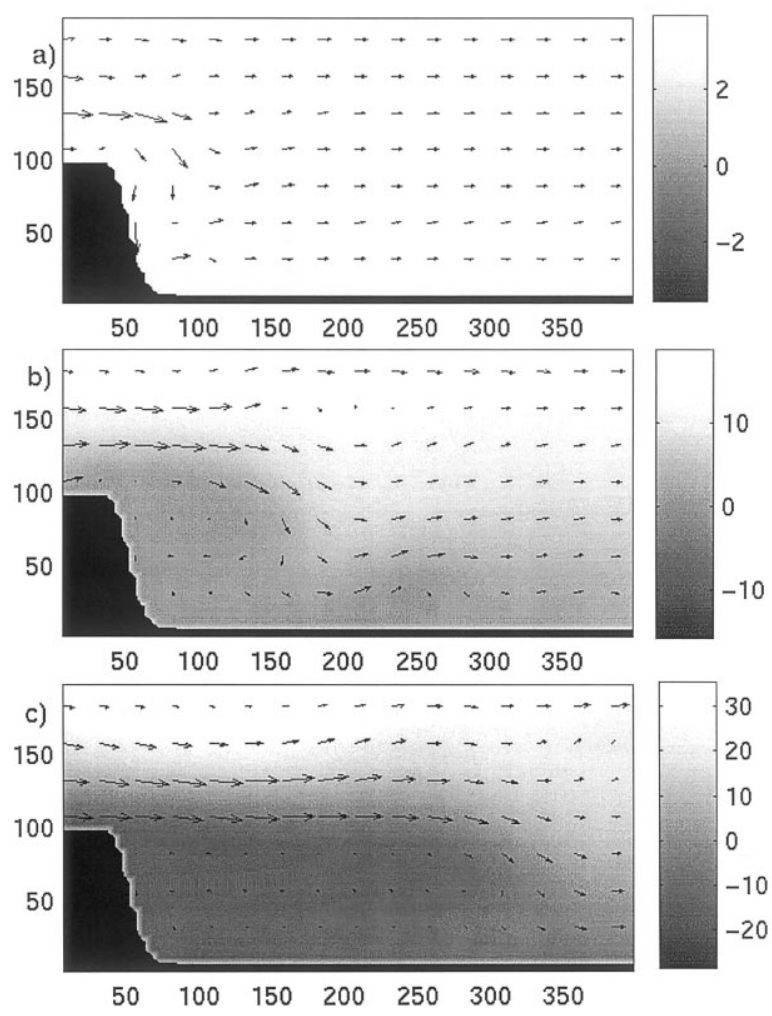

Figure 6. Barotropic velocities and sea surface elevation at day 50 for different values of the alongshore wind stress: a) $0.02 \mathrm{~N} . \mathrm{m}^{-2}$ (maximum velocity: $16 \mathrm{~cm} . \mathrm{s}^{-1}$, averaged velocity: $5 \mathrm{~cm} . \mathrm{s}^{-1}$ ), b) $0.1 \mathrm{~N} . \mathrm{m}^{-2}$ (maximum velocity: $74 \mathrm{~cm} . \mathrm{s}^{-1}$, averaged velocity: 21 $\mathrm{cm} \cdot \mathrm{s}^{-1}$ ), c) $0.2 \mathrm{~N} \cdot \mathrm{m}^{-2}$ (maximum velocity: $130 \mathrm{~cm} . \mathrm{s}^{-1}$, averaged velocity: $41 \mathrm{~cm} . \mathrm{s}^{-1}$ ). The horizontal coordinates are in kilometers and the gray scale range for the free surface elevation is in centimeters.

is in agreement with the analytical solution (figure 6). The characteristic velocities are ranging from 0.05 $\mathrm{m} . \mathrm{s}^{-1}$ to $0.4 \mathrm{~m} . \mathrm{s}^{-1}$. The associate scaling parameters are then, using the same characteristic numbers as in section 5 :

- $R o \sim 6 \times 10^{-3}$ to $5.3 \times 10^{-2}$

- $\operatorname{Re}_{\text {biharm }} \sim 3.1 \times 10^{4}$ to $2.7 \times 10^{5}$

- $R e_{\text {friction }} \sim 0.23$ to 2.1

- $E k=2.6 \times 10^{-2}$ as in the reference experiment.

This corresponds to the same regime as the reference experiment: small Rossby and Ekman numbers, large viscous Reynolds number and friction Reynolds number $\sim O(1)$. The results of Becker (1991) tell us that if $R e_{\text {friction }}<1$, detachment should not occur, but the presence of bottom topography induces other detachment processes, resulting from input of vorticity by vortex stretching, friction slope torque or wind stress slope torque. For example, a detachment process can be simply explained by absolute vorticity conservation. If a water particle follows an isobath cyclonicaly bent with the coast on the left like an equatorward current around Cape Columbine, it acquires a cyclonic vorticity, $\xi<0$. For the sake of absolute vorticity conservation $((f+\xi) / H=c s t$. $)$, the particle is displaced offshore onto a deeper isobath $(f<0)$. The particle needs a steeper turn to go back to the first isobath, hence stronger negative relative vorticity. This moves the particle into deeper waters and so on, then detachment occurs. This shows that the presence of bottom topography can favor detachment of the flow for an equatorward eastern boundary current past a cape. In contrast, bottom topography can be a stabilization process for a poleward eastern boundary current. Hence, Becker's (1991) criterion does not apply in our case, and we still have detachment even for a small frictional Reynolds parameter (figure 6 top).

To characterize the size of the eddy as a function of the wind stress, we chose to measure the distance between the tip of the cape and the place where the flow is the strongest towards the coast. The alongshore eddy length given by this method is proportional to the wind stress (figure 7) and the trend is in agreement with the characteristic length scale found in section 6.2 (figure 6 top, middle, bottom and figure 7).

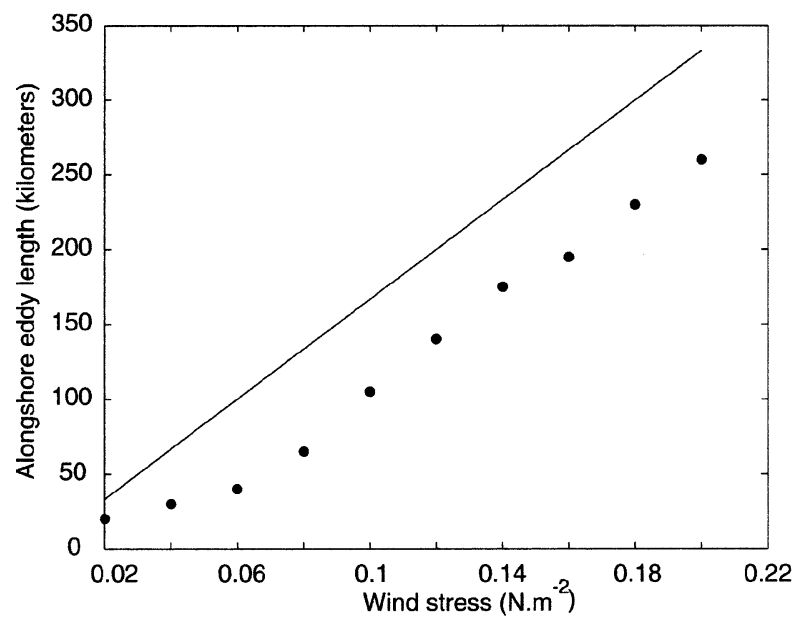

Figure 7. Alongshore extension of the eddy at day 50 as a function of the wind stress. Comparison with the characteristic length scale: $l=H \tau / \rho r^{2}$. 

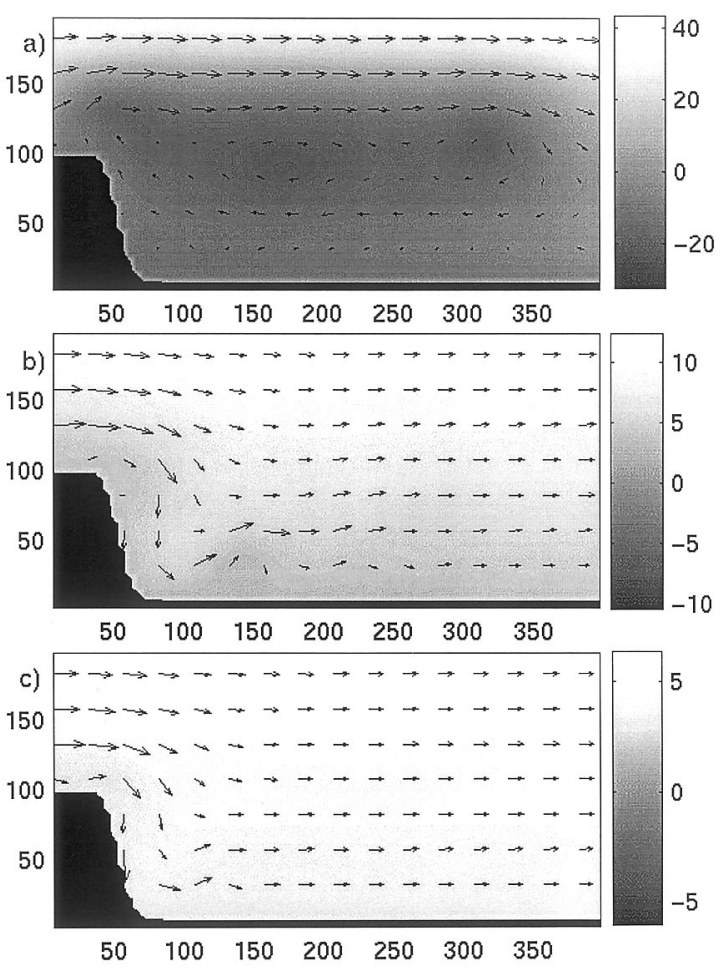

Figure 8. Barotropic velocities and sea surface elevation at day 100 forced by a constant wind stress $\left(0.05 \mathrm{~N} . \mathrm{m}^{-2}\right)$, for different values of the linear bottom coefficient $r$ : a) $r=0.5-10^{-4} \mathrm{~m} . \mathrm{s}^{-1}$ (maximum velocity: $129 \mathrm{~cm} . \mathrm{s}^{-1}$, averaged velocity: $49 \mathrm{~cm} . \mathrm{s}^{-1}$ ), b) $r=2.5 \times 10^{-4\}} \mathrm{m} . \mathrm{s}^{-1}$ (maximum velocity: $35 \mathrm{~cm} . \mathrm{s}^{-1}$, averaged velocity: $14 \mathrm{~cm} . \mathrm{s}^{-1}$ ), c) $r=5.0 \times 10^{-4} \mathrm{~m} . \mathrm{s}^{-1}$ (maximum velocity: $19 \mathrm{~cm} . \mathrm{s}^{-1}$, averaged velocity: $8 \mathrm{~cm} . \mathrm{s}^{-1}$ ). The horizontal coordinates are in kilometers and the gray scale range for the free surface elevation is in centimeters.

There is even though an approximately constant discrepancy $(\sim 50 \mathrm{~km})$ between the numerical results and the characteristic length scale, that reveals that something is missing in deriving the analytical length scale.

Within the eddy, the flow is weak and the alongshore velocities are positive for $y<20 \mathrm{~km}$ and $y>100 \mathrm{~km}$ and negative around $y=60 \mathrm{~km}$. The constant nature of this pattern might be related to the slope of the shelf or to the size of the cape.

\subsection{Influence of the linear bottom friction coefficient}

Ten more numerical experiments with wind stress fixed at $0.05 \mathrm{~N} . \mathrm{m}^{-2}$ were conducted to explore the effects of the linear bottom friction coefficient. This parameter varies from $0.5 \times 10^{-4} \mathrm{~m} . \mathrm{s}^{-1}$ to $5 \times 10^{-4}$ $\mathrm{m} . \mathrm{s}^{-1}$. For low bottom friction values, the solution was not yet stationary at day 50 , so day 100 is analyzed. The mean velocities are again the same order of magnitude as predicted by the analytical calculations (figure 8). In the same manner as in the previous section, the different characteristic velocities and characteristic parameters are derived. For increasing $r$, they follow the range:

- $U \sim 0.5$ to $0.08 \mathrm{~m} . \mathrm{s}^{-1}$

- $R o \sim 6 \times 10^{-2}$ to $10^{-3}$

- $R e_{\text {biharm }} \sim 3 \times 10^{5}$ to $5 \times 10^{4}$

- $R e_{\text {friction }} \sim 15$ to 0.2

- $E k=4.3 \times 10^{-3}$ to $4.3 \times 10^{-2}$.

Again the Rossby and Ekman numbers are small and the viscous Reynolds number is very large. But for this set of experiments, the frictional Reynolds number which is the most important in the control of the detachment process, varies along two orders of magnitude. Because this number is equivalent to the island wake parameter of Wolanski et al. (1984), we can expect a domination of bottom friction for low values and instabilities for large values. For low bottom friction, the alongshore size of the eddy does not match the characteristic length scale and three small eddy cells keep on moving inside a global structure (figure $8 a$ ). The solution is not yet steady at day 100 and different dynamical balances should exist. It appears that in this experiment, we are in the eddy shedding regime.

For $r>10^{-4} \mathrm{~m} . \mathrm{s}^{-1}$ and corresponding $R e_{\text {friction }}<$ 7.5, the eddy size does scale with $r^{-2}$ (figure 9), but as in the previous section this size is not in agreement with the characteristic length scale.

This analysis confirms the key role of bottom friction in controlling the detachment processes and the importance of parameterizing it carefully.

In summary, these experiments show that interactions between a barotropic current forced by an upwelling favorable wind and the topographical features of Cape Columbine and St Helena Bay generate a cyclonic eddy extending northward from the tip of Cape Columbine. The eddy vorticity balance is mostly controlled through a balance between advection and bottom friction. Hence, it is possible to estimate the size of the cyclone when the solution 
becomes stationary (after 50 days of constant alongshore wind forcing) and for a certain limited range of bottom friction parameter.

\section{THE "WATER AGE" TRACER}

To illustrate the effects of the development of the eddy on the coastal and offshore circulation, a tracer $\mathrm{T}$ has been introduced in the model. It follows a time forced advective equation:

$\frac{\partial T}{\partial t}+\bar{u} \frac{\partial T}{\partial x}+\bar{v} \frac{\partial T}{\partial y}=1$

The number 1 on the right of equation (22) is the time forcing term. To be consistent with the numerical SCRUM model, the equation (22) has been rewritten in the flux form and for the sake of numerical stability, biharmonic viscosity has been included.

$\frac{\partial}{\partial t}(D T)+\frac{\partial}{\partial x}(D \bar{u} T)+\frac{\partial}{\partial y}(D \bar{v} T)=D+v_{4} \hat{\Delta}\left(\frac{\hat{\Delta}(T)}{D}\right)$ $v_{4}$ has been kept as small as possible and because in all experiments $R e_{\text {biharm }}$ is of the order of $O\left(10^{5}\right)$, viscosity should not perturb the solution. $T$ is kept at zero at the upwind boundary. Away from the boundary, $T$ increments continuously. To test this, $T$ has been introduced in an experiment with a rectilinear coastline and a flat bottom. Using the former analytical results, at day 50, when the solution is stationary equation (9), the time since a water particle has left the upwind boundary is only $x$-dependent:

$T=\frac{\rho r x}{\tau}$

The rectilinear coastline numerical experiment is in agreement with this solution (figure not shown). From the outputs at day 100 of the reference experiment, we can see that the distribution of $T$ over the model domain is strongly influenced by the topography and the development of the eddy in the lee of the cape (figure 10b). In the offshore area $(y>200 \mathrm{~km}), T$ increases almost linearly towards the right side of the domain (the downwind and equatorward directions), this illustrates the advection of the water as it flows toward the equatorward side of the model domain. In

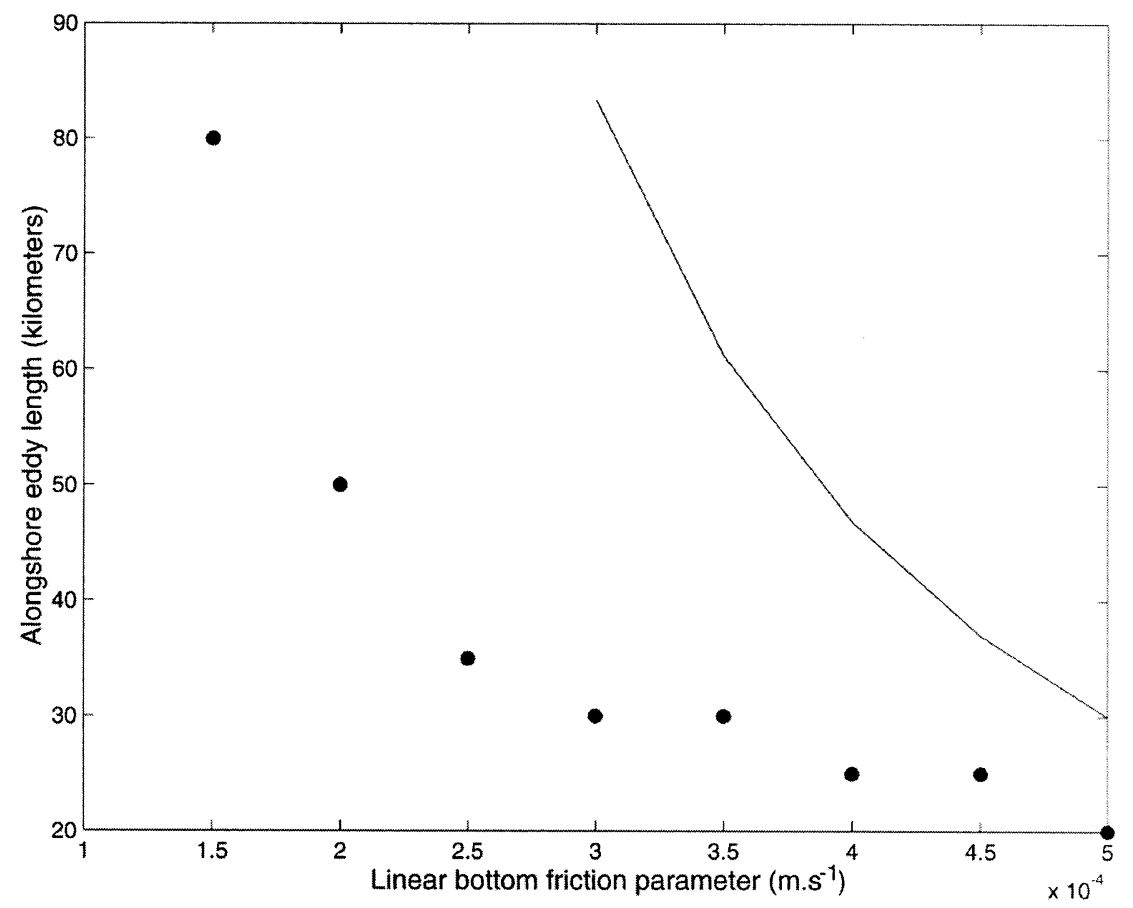

Figure 9. Alongshore extension of the eddy at day 100 as a function of the linear bottom friction parameter $\mathrm{r}$. Comparison with the characteristic length scale: $l=H \tau / \rho r^{2}$. 

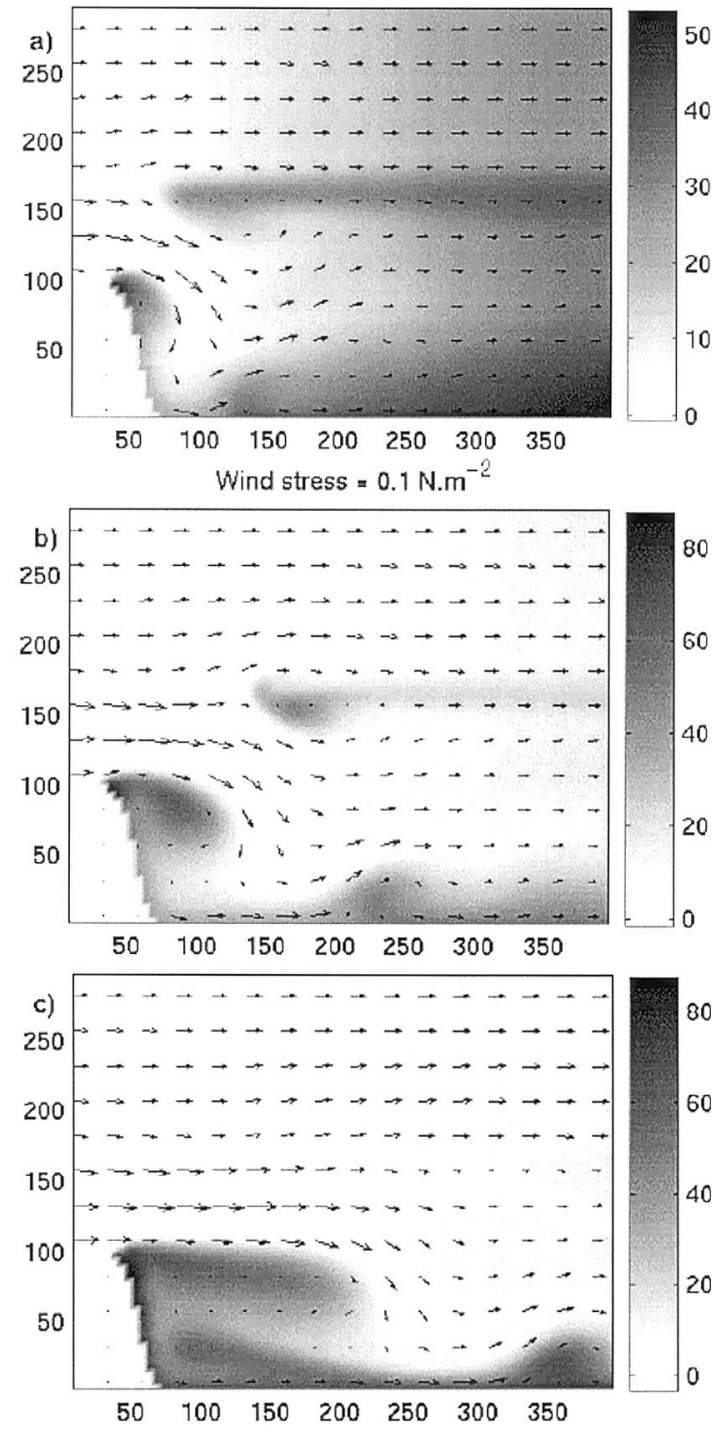

Figure 10. Spatial distribution of the water age tracer at day 100 for experiments similar to the reference experiment. The alongshore wind stress is fixed during each experiment at: (a) 0.05 N.m ${ }^{-2}$, (b) $0.1 \mathrm{~N} . \mathrm{m}^{-2}$, (c) $0.15 \mathrm{~N} . \mathrm{m}^{-2}$. The horizontal coordinates are in kilometers and the gray scale range for the water age tracer is in days.

the coastal area, $T$ reaches a maximum (90 days) in the vicinity of the cape $(x=40 \mathrm{~km}, y=100 \mathrm{~km})$ and in the downstream nearshore area (figure 10b, $T=60$ days, $x=80 \mathrm{~km}, y=90 \mathrm{~km}$ ). It reaches a local maximum inside the shelf break meander where the velocities are weak (figure 10b, $T=45$ days, $x=170 \mathrm{~km}$, $y=160 \mathrm{~km}$ ). For a wind $50 \%$ stronger than the reference experiment, whereas the area of strong $T$ values has increased with the size of the eddy, the maximal value of $T$ does not vary significantly from the reference experiment (figure 10c). In this experiment, the local maximum on the shelf edge has disappeared. For a wind $50 \%$ weaker, the eddy is small $(<40 \mathrm{~km})$ and its contribution doesn't affect dramatically the tracer distribution (figure 10a), even though, there is a local maximum at the tip of the cape (figure 10a, $T=40$ days, $x=45 \mathrm{~km}, y=95 \mathrm{~km}$ ).

In order to investigate the effects of the intensity of the wind forcing on the distribution of $T$, several successive runs of the model are performed using values of wind stress increasing from $0.02 \mathrm{~N} . \mathrm{m}^{-2}$ to $0.2 \mathrm{~N} . \mathrm{m}^{-2}$ by steps of $0.02 \mathrm{~N} . \mathrm{m}^{-2}$ (figure not shown). The spatial distribution of $\mathrm{T}$ is extracted at day 50. For low wind forcing and weak flow detachment (ranging from 0.02 to $0.06 \mathrm{~N} . \mathrm{m}^{-2}$ ), there are small differences between the coast and the offshore areas; $T$ increases almost steadily over the entire domain toward the right boundary. For moderate wind forcing (ranging from 0.06 to $0.14 \mathrm{~N} . \mathrm{m}^{-2}$ ), the eddy starts to develop downwind of the cape. In the offshore area, the distribution of $T$ is not affected by the eddy. But in the coastal domain, the development of the eddy induces an increase of the age of the water retained in the eddy and on the coastal side of the eddy. $T$ reaches a maximum value of about 30 days in the nearshore domain. For strong wind forcing (greater than $0.14 \mathrm{~N} \cdot \mathrm{m}^{-2}$ ), the size of the eddy grows as the wind but $T$ does not increase in the eddy.

These results are summarized in figure 11. In order to allow comparison between the offshore and coastal regions, $T$ is averaged over two areas: a coastal/eddy area $\left(T_{\text {coast }}: x=25\right.$ to $150 \mathrm{~km}$ and $y=0$ to $\left.110 \mathrm{~km}\right)$ and an offshore area ( $T_{\text {off }}: x=25$ to $150 \mathrm{~km}$ and $y=110$ to $200 \mathrm{~km}) . T_{\text {coast }}$ and $T_{\text {off }}$ are calculated at day 50 for each of the successive runs performed with wind stress ranging from $0.02 \mathrm{~N} . \mathrm{m}^{-2}$ to $0.2 \mathrm{~N} . \mathrm{m}^{-2}$. In the offshore domain, $T_{\text {off }}$ decreases as an inverse function of the wind stress: the stronger is the wind, the stronger is the advection towards the right side of the model domain. In the coastal domain, $T_{\text {coast }}$ decreases as the wind forcing increases from low to moderate (from 0.02 to $0.06 \mathrm{~N} . \mathrm{m}^{-2}$ ). In that range of wind forcing, the cape has little influence on the coastal circulation, the eddy size remains small compared to the size of the cape. For stronger wind 
forcing, the effect of the eddy on the coastal circulation is highly noticeable. For wind forcing ranging from 0.06 to $0.14 \mathrm{~N} . \mathrm{m}^{-2}$, the size of the eddy expands and $T_{\text {coast }}$ increases simultaneously with the wind. From 0.14 to $0.2 \mathrm{~N} . \mathrm{m}^{-2}$, the size of the eddy reaches or expands over the domain where $T_{\text {coast }}$ is calculated and $T_{\text {coast }}$ reaches a plateau at a value of 18 days.

The variability of $T_{\text {coast }}$ and $T_{\text {off }}$ over a wide range of wind forcing illustrates the effects of the development of the eddy on the coastal and offshore circulation. When the wind forcing is strong enough (greater than $0.06 \mathrm{~N} . \mathrm{m}^{-2}$ ), the eddy induces a pronounced recirculation in the coastal domain, but the offshore area is unaffected. Looking back at figure 3, one can see that while some water may enter the eddy as a slow equatorward flow nearshore, most of the water has circulated around the eddy and then entered from the bay side. The relative increase of $T$ in the coastal eddy domain, when compared to the value in the offshore area, is an important consequence of the development of the eddy.

\section{DISCUSSION}

The presence of the eddy contributes to the formation of two distinct patterns of circulation within the model domain: in the offshore area, the circulation is predominantly alongshore; in the coastal area, the circulation is dominated by a cyclonic eddy and by the associated recirculation pattern. The size of the eddy is positively related to the intensity of wind forcing. The recirculation induced by the eddy tends to isolate the nearshore area from the offshore do- main. It limits the cross-shelf exchange of water and retains water particles within the coastal domain, thus providing a mechanism for retention. Retention in this coastal domain is then closely related to the wind induced recirculation pattern. The next step in our analysis is to evaluate the strength of retention as a function of the strength of the wind forcing.

A true retention index would have been given by the residence time computed from the advection fields provided by the model. However, the difference between the age of the water in the coastal domain $\left(T_{\text {coast }}\right)$ and the offshore domain $\left(T_{\text {off }}\right)$ can be used as a proxy to evaluate the intensity of the retention. The variability of this index (further noted as $R_{i}$ ) gives an indication on how the aging of the water differs between the two areas, a positive (negative) value indicates water particles being older (younger) in the coastal domain relative to the offshore area. From a biological point of view, this offshore-inshore gradient can be used to evaluate the potential advantage for larvae to be located in the coastal area. The variability of $R_{i}$ as a function of wind stress is presented on figure 12. $R_{i}$ increases as the wind forcing increases, it reaches a maximum (18 days) value for a wind stress of $1.8 \mathrm{~N} \cdot \mathrm{m}^{-2}$ and then appears to level off or decrease. As mentioned before, $R_{i}$ represents the difference between the coastal and the offshore areas in the aging process of the water particles and $R_{i}$ should not be used as an indicator of residence times within the bight.

This positive relationship between wind forcing and the retention index suggests that, in an upwelling system, wind-induced circulation patterns, such as an upwelling plume, may provide retention on the coastal side of the plume.
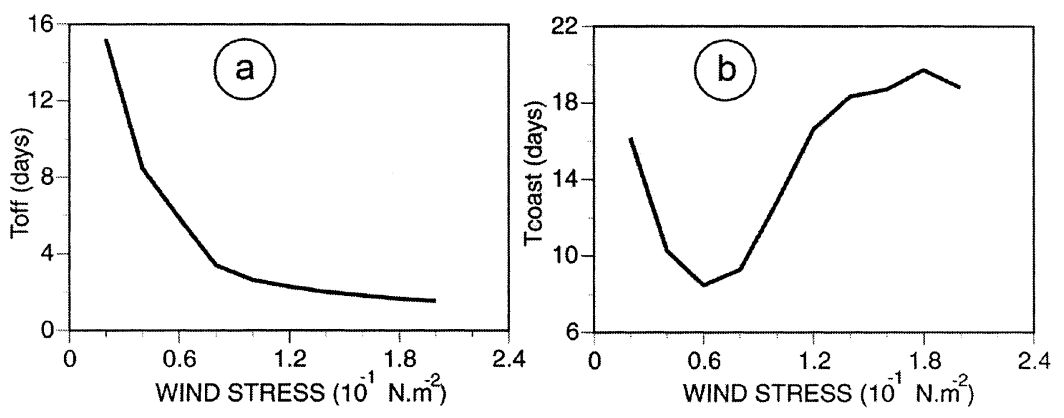

Figure 11. Value of the water age tracer, $T_{\text {off }}$ (a) and $T_{\text {coast }}$ (b) at day 50 for values of wind stress forcing ranging from $0.02 \mathrm{~N} . \mathrm{m}^{-2}$ to $0.2 \mathrm{~N} . \mathrm{m}^{-2}$ by steps of $0.02 \mathrm{~N} . \mathrm{m}^{-2}$. 


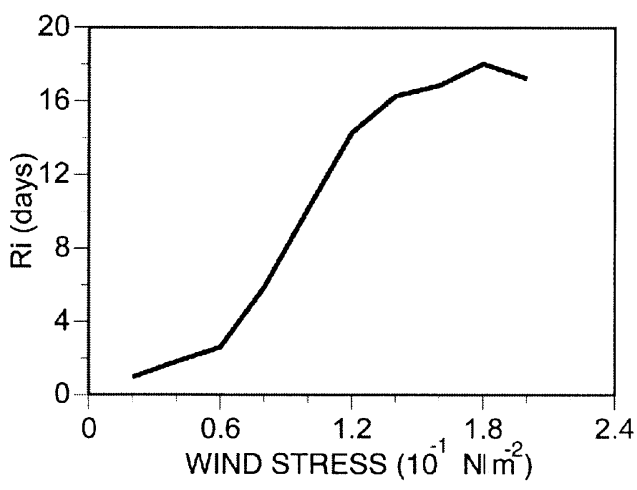

Figure 12. The relationship between the retention index $R_{i}$ and wind stress, ranging from $0.02 \mathrm{~N} . \mathrm{m}^{-2}$ to $0.2 \mathrm{~N} . \mathrm{m}^{-2}$ by steps of 0.02 N.m ${ }^{-2}$.

Further, stronger upwelling favorable winds can enhance retention within the nearshore area despite the intensification of the offshore flow related to the upwelling. Such structures, providing a positive coupling between upwelling and retention, have been documented in several upwelling systems (Graham and Largier, 1997; Roy, 1998).

In the Benguela upwelling system, most of the spawning occurs in late spring and summer, during the peak season of the upwelling. Fish eggs and larvae are transported from the spawning ground to the West Coast upwelling by a coastal jet. With the classical wind-driven coastal upwelling circulation structure of offshore transport of surface water, larvae will tend to be transported in the offshore domain and be lost. However, our modeling experiment shows that the Cape Columbine plume and the associated coastal recirculation in St Helena Bay provide a retention mechanism allowing the larvae to be retained within the productive coastal domain and thereby to avoid dispersion in the offshore area.

\section{CONCLUSION}

We used an idealized numerical model to understand the interactions between the wind-induced circulation on the shelf and topographical features such as Cape Columbine and St Helena Bay. The setting of the model is based on the assumption that the circulation on the shelf follows barotropic dynamics. Hence, the barotropic equations of motion have been solved in a periodic channel and over analytical bathymetry.
They have been constrained by a constant upwelling favorable wind stress and a linear bottom friction. Despite these simplifications, it appears that the model is able to produce a cyclonic eddy in St Helena Bay that corresponds to the observed circulation pattern (Holden, 1985; Shannon, 1985). The shape and size of this eddy are in relative agreement with the results of Oey (1996) and Boyer and Tao (1987). The eddy creates a dynamical barrier, limiting the exchanges between the nearshore area and the shelf edge domain.

Diagnostic analysis shows that the circulation is overwhelmed by the balance between the Coriolis acceleration and the pressure gradient. The velocities offshore are linked to a balance between wind stress and bottom friction and the external part of the eddy follows cyclo-geostrophic dynamics. When the numerical solution reaches a stationary state, a vorticity analysis reveals that a balance between the curl of advection and the curl of bottom friction controls the eddy dynamics. This balance gives a characteristic eddy length scale proportional to the wind stress and inversely proportional to the square of the linear bottom friction parameter. Several numerical experiments using a wide range of wind stress and bottom friction values, indicate that the alongshore extension of the eddy follows the trends of this length scale when the dynamics are in the attached-cyclonic-eddy regime.

A tracer of the age of the water is introduced to evaluate the intensity of recirculation generated by the eddy in the coastal domain. This tracer is used as a proxy for retention and to explore the relation between the intensity of retention and wind forcing. In accordance with previous observations, the model simulation indicates that the plume induces retention on the "shadow" (coastal) side of the plume. In regions where fish spawning occurs during the upwelling season, fish have successfully used such structures to reproduce (Roy et al., 1989; Bakun, 1996, 1998). In the Benguela upwelling system, St Helena Bay is recognized as the main nursery ground off the West coast where juvenile fish are concentrated (Hutchings, 1992), suggesting that this retention mechanism may be critical to recruitment success. Interannual fluctuations of the upwelling intensity will affect the development of the Cape Columbine upwelling plume and simultaneously alter the inten- 
sity of retention in St Helena Bay. Therefore, the quantification of how retention is affected by interannual wind forcing is an important step toward a better understanding of the environmental processes controlling fish recruitment variability. One must bear in mind that environmental control of recruitment variability involves several processes, (see for example the triad of environmental processes identified by Bakun, 1996). Retention might play an important role during one or several stages of the larvae development but other processes, such as food availability or transport from the jet to the coastal area, are other important environmental processes to take into account. The positive contribution of increased upwelling for retention can be overbalanced by the detrimental effect of increased mixing when wind reaches a value over a threshold. In upwelling areas, the existence of multi-variable and non-linear relationships between recruitment and upwelling intensity is a recurrent pattern resulting from the interaction between several environmental process (Cury and Roy, 1989; Cury et al., 1995; Durand et al., 1998).

\section{Acknowledgements}

This study was supported by the French project "Programme National sur le Déterminisme du Recrutement (P.N.D.R.)", by the French "Institut de Recherche pour le Développement (I.R.D.)" and by the South-African-French VIBES project. Thanks to Pr. G. Brundrit and to two anonymous reviewers for their comments on an earlier version of the manuscript. G. Bailey (Marine and Coastal Management (M.\&C.M.), Cape Town South Africa) has provided us with hydrographic data from St Helena Bay. Special thanks to F. Maupas for discussion on the destabilization processes induced by variation in topography.

\section{REFERENCES}

Bailey, G.W., Chapman, P., 1985. The nutrient status of the St Helena bay region in February 1979. In: Shannon, L.V. (Ed.), South African Ocean Colour Experiment. Sea Fisheries Research Institute, Cape Town, pp. 125-145.

Bakun, A., 1996. Patterns in the Ocean: Ocean Processes and Marine Population Dynamics, Univ. California Sea Grant, San Diego, California, USA, in cooperation with Centro de Investigaciones Biolgicas de Noroeste, La Paz, Baja California Sur, Mexico, 323 pp.
Bakun, A., 1998. Ocean triads and radical interdecadal stock variability: bane and boon for fisheries management. In: Pitcher, T., Hart, P.J.B., Pauly, D. (Eds.), Reinventing fisheries management. Chapman and Hall, pp. 331-358.

Batteen, M.L., 1997. Wind-force modeling studies of currents, meanders, and eddies in the California Current system. J. Geophys. Res. 102 (1997), 985-1010.

Becker, A., 1991. The separated flow past a cylinder in a rotating frame. J. Fluid Mech. 224 (1991), 117-132.

Boyer, D.L., Tao, L., 1987. On the motion of linearly stratified rotating fluids past capes. J. Fluid Mech. 180 (1987), 429-449.

Boyer, D.L., Cheng, R., Chabert D'Hiéres, G., Didelle, H., 1987. On the formation of vortices from side-wall mounted obstacles in rotating systems. Dyn. Atmos. Oceans 11, 59-86.

Brink, K.H., 1998. Wind-driven currents over the continental shelf. In: Brink, K.H., Robinson, A.R. (Eds.), The Sea, vol. 10, The Global Coastal Ocean: Processes and Methods. Wiley, pp. $3-20$.

Clark, A.J., Brink, K.H., 1985. The response of stratified, frictional flow of shelf and slope waters to fluctuating large-scale, lowfrequency wind forcing. J. Phys. Oceanogr. 15, 439-493.

Crepon, M., Richez, C., Chartier, M., 1984. Effects of Coastline Geometry on Upwellings. J. Phys. Oceanogr. 14, 1365-1382.

Csanady, G.T., 1978. The arrested topographic wave. J. Phys. Oceanogr. 8, 47-62.

Csanady, G.T., 1982. Circulation in the Coastal Ocean. D. Reidel Publishing Company, Dordrecht, 279 pp.

Csanady, G.T., 1998. The non-wavelike response of a continental shelf to wind. J. Mar. Res. 56, 773-788.

Cury, P., Roy, C., 1989. Optimal environmental window and pelagic fish recruitment success in upwelling areas. Can. J. Fish. Aquat. Sci. 46, 670-680.

Cury, P., Roy, C., Mendelssohn, R., Bakun, A., Husby, D.M., 1995. Moderate is better: exploring nonlinear climatic effect on the Californian northern anchovy. Can. Spec. Publ. Fish. Aquat. Sci. 121, 41-424.

Davies, P.A., Besley, P., Boyer, D.L., 1990. An experimental study of flow past a triangular cape in a linearly stratified fluid. Dyn. Atmos. Oceans 8, 497-528.

Durand, M.-H., Cury, P., Mendelssohn, R., Roy, C., Bakun, A., Pauly, D., 1998. Global versus local changes in upwelling systems. Editions ORSTOM, Paris, 558 pp.

Graham, W.M., Largier, J.L., 1997. Upwelling shadows as nearshore retention sites: the example of northern Monterey Bay. Cont. Shelf Res. 17, 509-532.

Hedström, K.S., 1997. User's Manual for an S-Coordinate Primitive Equation Ocean Circulation Model (SCRUM) Version 3.0, Inst. Mar. Coast. Sci., Rutgers Univ., 1997, 116 pp.

Holden, C.J., 1985. Currents in St Helena Bay inferred from radio-tracked drifters. In: Shannon, L.V. (Ed.), South African Ocean Colour Experiment. Sea Fish. Res. Inst, Cape Town, pp. 97-109.

Hutchings, L., 1992. Fish harvesting in a variable, productive environment. S. Afr. J. mar. Sci. 12, 297-318. 
Jury, M.R., 1985. Mesoscale variations in summer winds over the Cape Columbine-St Helena Bay region, South Africa. S. Afr. J. mar. Sci. 3, 77-88.

Kamstra, F., 1985. Environmental features of the southern Benguela with special reference to the wind stress. In: Shannon, L.V. (Ed.), South African Ocean Colour Experiment. Sea Fish. Res. Inst, Cape Town, pp. 13-27.

Klinger, B.A., 1993. Gyre formation at a corner by rotating barotropic coastal flows along a slope. Dyn. Atmos. Oceans 19, 27-63.

Kundu, P.K., 1990. Fluid Mechanics. Academic Press, 629 pp.

Lamberth, R., Nelson, G., 1987. Field and analytical drogue studies applicable to the St Helena bay area off South Africa's west coast. S. Afr. J. mar. Sci. 5, 163-169.

Narimousa, S., Maxworthy, T., 1989. Application of a laboratory model to the interpretation of satellite and field observations of coastal upwelling. Dyn. Atmos. Oceans 13, 1-46.

Nelson, G., Hutchings, L., 1983. The Benguela upwelling area. Prog. Oceanog. 12, 333-356.

Oey, L.-Y., 1996. Flow around a coastal bend: A model of the Santa Barbara Channel eddy. J. Geophys. Res. 101, 1666716682.

Parrish, R.H., Bakun, A., Husby, D.M., Nelson, C.S., 1983. Comparative climatology of selected environmental processes in relation to eastern boundary current pelagic fish reproduction. FAO Fish. Rep. 291, 731-777.
Pattiaratchi, C., James, A., Collins, M., 1986. Island wakes and headland eddies: a comparison between remotely sensed data and laboratory experiments. J. Geophys. Res. 92, 783-794.

Peffley, M.B., O’Brien, J.J., 1975. A three-dimensional simulation of coastal upwelling of Oregon. J. Phys. Oceanogr. 6, 164-180.

Roy, C., Cury, P., Fontana, A., Belvèze, H., 1989. Stratégies spatio-temporelles de la reproduction des clupéidés des zones d'upwelling d'Afrique de l'Ouest. Aquat. Liv. Res. 2, 21-29.

Roy, C., 1998. Upwelling-induced retention area: a mechanism to link upwelling and retention processes. S. Afr. J. mar. Sci. 19, 89-98.

Shannon, L.V., 1985. The Benguela ecosystem part I. Evolution of the Benguela, physical features and processes. Oceanogr. Mar. Biol. Ann. Rev. 23, 105-182.

Signell, R.P., Geyer, W.R., 1991. Transient eddy formation around headlands. J. Geophys. Res. 96, 2561-2575.

Song, Y., Haidvogel, D., 1994. A semi-implicit ocean circulation model using a generalized topography-following coordinate system. J. Comp. Physics 115, 228-244.

Taunton-Clark, J., 1985. The formation, growth and decay of upwelling tongues in response to the mesoscale wind field during summer. In: Shannon, L.V. (Ed.), South African Ocean Colour Experiment. Sea Fish. Res. Inst, Cape Town, pp. $47-61$.

Wolanski, E., Imberger, J., Heron, M.L., 1984. Island wakes in shallow coastal waters. J. Geophys. Res. 89, 10553-10569. 